\title{
Flow injection analysis using carbon film resistor electrodes for amperometric determination of ambroxol
}

\author{
Fabiana S. Felix ${ }^{\mathrm{a}}$, Christopher M.A. Brett ${ }^{\mathrm{b}}$, Lúcio Angnes ${ }^{\mathrm{a}, *}$ \\ a Instituto de Química, Universidade de São Paulo, 05508-000 São Paulo, Brazil \\ b Departamento de Química, Universidade de Coimbra, 3004-535 Coimbra, Portugal
}

\section{A R T I C L E I N F O}

\section{Article history:}

Received 29 November 2007

Received in revised form 12 February 2008

Accepted 14 February 2008

Available online 19 February 2008

\section{Keywords:}

Flow injection analysis

Carbon film electrodes

Ambroxol

Amperometry

Pharmaceutical products

\begin{abstract}
A B S T R A C T
Flow injection analysis (FIA) using a carbon film sensor for amperometric detection was explored for ambroxol analysis in pharmaceutical formulations. The specially designed flow cell designed in the lab generated sharp and reproducible current peaks, with a wide linear dynamic range from $5 \times 10^{-7}$ to $3.5 \times 10^{-4} \mathrm{~mol} \mathrm{~L}^{-1}$, in $0.1 \mathrm{~mol} \mathrm{~L}^{-1}$ sulfuric acid electrolyte, as well as high sensitivity, $0.110 \mathrm{~A} \mathrm{~mol}^{-1} \mathrm{~L} \mathrm{~cm}^{-2}$ at the optimized flow rate. A detection limit of $7.6 \times 10^{-8} \mathrm{~mol} \mathrm{~L}^{-1}$ and a sampling frequency of 50 determinations per hour were achieved, employing injected volumes of $100 \mu \mathrm{L}$ and a flow rate of $2.0 \mathrm{~mL} \mathrm{~min}^{-1}$. The repeatability, expressed as R.S.D. for successive and alternated injections of $6.0 \times 10^{-6}$ and $6.0 \times 10^{-5} \mathrm{~mol} \mathrm{~L}^{-1}$ ambroxol solutions, was 3.0 and $1.5 \%$, respectively, without any noticeable memory effect between injections. The proposed method was applied to the analysis of ambroxol in pharmaceutical samples and the results obtained were compared with UV spectrophotometric and acid-base titrimetric methods. Good agreement between the results utilizing the three methods and the labeled values was achieved, corroborating the good performance of the proposed electrochemical methodology for ambroxol analysis.
\end{abstract}

(c) 2008 Elsevier B.V. All rights reserved.

\section{Introduction}

Ambroxol, trans-4-[(2-amino-3,5-dibromobenzyl)amino]cyclohexanol or 2-amino-3,5-dibromo- $N$-[trans-4-hydroxycyclohexyl]benzylamine, is an expectorant agent which leads to bronchial secretion due to its mucolytic properties. It is administered as the hydrochloride in daily doses of $30-120 \mathrm{mg}$ and is available commercially as syrups, granules, tablets, or in solutions, utilized in the injectable form or for inhalation [1].

Several analytical methods for ambroxol quantification in biological fluids and pharmaceutical formulations are described in the literature. These include (TLC) densitometry [2], high performance liquid chromatography [3-12], capillary electrophoresis [13-15], Raman-spectroscopy [16,17], UV-spectrophotometry [18,19], gas chromatography [20], voltammetry [21,22] and chromatography with amperometric detection [23]. The British Pharmacopoeia recommends potentiometric titration as the official method [24]. Only a few automated analytical procedures for the quantification of this

\footnotetext{
* Corresponding author. Tel.: +55 113091 3828; fax: +55 1138155579

E-mail address: luangnes@iq.usp.br (L. Angnes).
}

drug have been reported, including liquid chromatography coupled with sequential injection analysis (SIA) $[25,26]$, spectrophotometry with flow injection analysis (FIA) [27] and potentiometry under flow conditions [28]. Some of the reported methods require time-consuming sample preparation or expensive instrumentation.

Flow injection methodology in association with amperometric detection has provided a means of automation in routine analyses with good selectivity and sensitivity. To our knowledge, FIA using amperometric detection for ambroxol determination has still not been explored.

In this work, carbon film electrodes have been employed as sensors in the electrochemical determination of ambroxol in different pharmaceutical samples, without any sample pretreatment. Cyclic voltammetry and flow injection analysis with amperometric detection were performed employing carbon films as working electrodes. These electrodes have a wide potential window, particularly after electrochemical pretreatment by cycling in acid media [29]. They have been characterized by electrochemical impedance spectroscopy [30] and have already been used in different applications such as trace metal analysis [31,32], biosensors [33-39] and pharmaceutical formulations analysis [40]. We will describe the 
application of these electrodes to the direct analysis of ambroxol in pharmaceutical products.

\section{Experimental}

\subsection{Reagents and solutions}

Sulfuric acid, sodium mono-hydrogen phosphate, potassium di-hydrogen phosphate, orthophosphoric acid, citric acid, benzoic acid, sodium sulfate and hydrochloric acid were acquired from Merck (Darmstadt, Germany). Ambroxol hydrochloride in its pure form was received as a gift from Arvensis Manipulation Pharmacy (São Paulo, Brazil), and was used without further purification. Ambroxol solutions were freshly prepared by dissolving the solid salt in supporting electrolyte. Two different supporting electrolytes were used during cyclic voltammetric experiments, phosphate buffer $\left(0.1 \mathrm{~mol} \mathrm{~L}^{-1}, \mathrm{pH} 2-12\right.$, in the preliminary experiments $)$ and sulfuric acid/sodium sulfate solution $\left(0.1 \mathrm{~mol} \mathrm{~L}^{-1}, \mathrm{pH} 1-4\right)$. The phosphate buffer solutions $\left(0.1 \mathrm{~mol} \mathrm{~L}^{-1}\right)$ were prepared by mixing solutions of sodium mono-hydrogen phosphate, potassium di-hydrogen phosphate, orthophosphoric acid or sodium hydroxide to give the desired $\mathrm{pH}$. Sulfuric/sodium sulfate solutions were prepared by mixing the required amounts of $\mathrm{H}_{2} \mathrm{SO}_{4}+\mathrm{Na}_{2} \mathrm{SO}_{4}$, both $0.1 \mathrm{~mol} \mathrm{~L}^{-1}$. All solutions were prepared with ultra pure water from a Millipore Milli-Q system (resistivity $\geq 18 \mathrm{M} \Omega \mathrm{cm}$ ). The pharmaceutical products analyzed were purchased in a local drugstore.

\subsection{Electrode preparation}

Electrodes were made from carbon film resistors of $2 \Omega$ nominal resistance. These resistors (built for electronic applications) are fabricated from ceramic cylinders with 4-6 mm length and $1.5 \mathrm{~mm}$ external diameter by pyrolytic deposition of carbon [29]. The resistor has two metal caps with wires as external contact placed over each end. One of the two caps was removed and the other was covered with epoxy resin. In this way the exposed cylindrical area of the electrode was $\sim 0.17 \mathrm{~cm}^{2}$. Before use, each electrode was electrochemically pretreated in $1.0 \mathrm{~mol} \mathrm{~L}^{-1}$ perchloric acid. This conditioning treatment is essential to ensure a good performance of the electrode $[29,30]$.

\subsection{Apparatus}

Voltammetric measurements were carried out with an EcoChemie Autolab PGSTAT 20 potentiostat (EcoChemie, The Netherlands). Cyclic voltammetry studies were done in a conventional $10 \mathrm{~mL}$ cell. The FIA/amperometric experiments were performed using the flow cell previously described [40] using a carbon film resistor as working electrode, an $\mathrm{Ag} / \mathrm{AgCl}_{\text {sat }}$ (sat. $\mathrm{KCl}$ ) as reference electrode and a stainless steel tube (positioned in the exit of the flow channel) as the auxiliary electrode. A peristaltic pump (Ismatec, Zurich, Switzerland) was used for fluid propulsion during the analyses. The standard solutions and ambroxol samples were introduced into the stream through a manually operated injection valve.

Spectrophotometric measurements were performed with a Hitachi U-2001 UV-vis spectrophotometer with a conventional quartz cell (optical path length $1.00 \mathrm{~cm}$ and total volume of $4 \mathrm{~mL}$ ). Potentiometric titration measurements were carried using a pHmeter (Quimis-model $400 \mathrm{M} 1 \mathrm{~S}$ ) with a combined glass electrode. All $\mathrm{pH}$ measurements were performed at room temperature, maintained at $25 \pm 2{ }^{\circ} \mathrm{C}$.

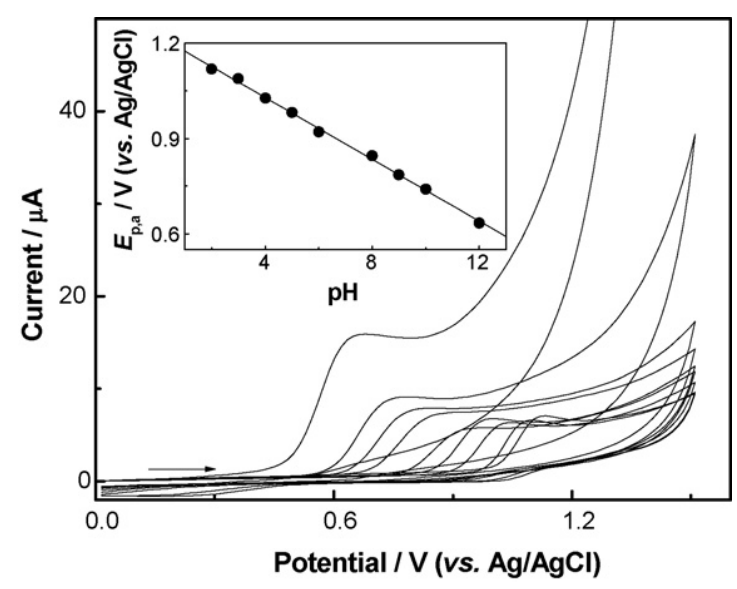

Fig. 1. Cyclic voltammograms of $2.0 \times 10^{-4} \mathrm{~mol} \mathrm{~L}^{-1}$ ambroxol in $0.1 \mathrm{~mol} \mathrm{~L}^{-1}$ phosphate buffer solution at different $\mathrm{pH}$ (from 2 to 12). Carbon film electrode area $=0.17 \mathrm{~cm}^{2}$. Scan rate $100 \mathrm{mV} \mathrm{s}^{-1}$.

\subsection{Preparation of the samples and standard solution}

For amperometric studies, aliquots of $120 \mu \mathrm{L}$ or $240 \mu \mathrm{L}$ of ambroxol samples (for syrups containing 30 and $15 \mathrm{mg}$ of drug, respectively) were transferred to a volumetric flask of $100 \mathrm{~mL}$ and filled with $0.1 \mathrm{~mol} \mathrm{~L}^{-1}$ sulfuric acid solution. Standard solutions of ambroxol were prepared daily in a similar way, in the same supporting electrolyte.

For the spectrophotometric studies, aliquots of $200 \mu \mathrm{L}$ and $400 \mu \mathrm{L}$ of ambroxol syrup (for samples containing 30 and $15 \mathrm{mg}$, respectively) were appropriately diluted in $0.1 \mathrm{~mol} \mathrm{~L}^{-1}$ hydrochloric acid solution, in accordance with the methodology described in the literature [21]. The calibration curve was done for ambroxol concentrations ranging from 1.0 to $5.0 \times 10^{-5} \mathrm{~mol} \mathrm{~L}^{-1}$ in $0.1 \mathrm{~mol} \mathrm{~L}^{-1}$ hydrochloric acid solution. The absorbances were measured at $307 \mathrm{~nm}$ [22].

The acid-base titration of the pharmaceutical formulation samples was done following the procedure described in the British Pharmacopoeia [24]. A known amount of hydrochloric acid was added to a chosen volume of syrup. The mixture was then titrated with a standardized $\left(0.1 \mathrm{~mol} \mathrm{~L}^{-1}\right)$ sodium hydroxide solution. Two equivalence points were observed, the first corresponding to the neutralization of the excess of hydrochloric acid and of the other acidic excipients such as citric, tartaric and benzoic acids. The second equivalence point was due to neutralization of the protonated ambroxol. The difference of titrant volume between these two equivalence points was then used to calculate the concentration of ambroxol $\left(\mathrm{p} K_{2}=7.16\right)[7]$.

\section{Results and discussion}

\subsection{Voltammetric studies}

The electrochemical behavior of ambroxol on the carbon film electrode was initially explored in phosphate medium, due to the ease of preparation of phosphate buffer solutions over a wide range of $\mathrm{pH}$. Fig. 1 shows cyclic voltammograms of $2.0 \times 10^{-4} \mathrm{~mol} \mathrm{~L}^{-1}$ ambroxol in $0.1 \mathrm{~mol} \mathrm{~L}^{-1}$ phosphate buffer over the $\mathrm{pH}$ range from 2 until 12. In all these conditions, the compound was oxidized presenting just one oxidation peak in the potential region studied, corresponding to an irreversible process. The peak potential for ambroxol oxidation showed a linear variation with increase of $\mathrm{pH}$ and shifted towards to a less positive potential. A slope of $49 \mathrm{mV}$ $\mathrm{pH}^{-1}$ (correlation coefficient of 0.998 ) was found over the whole 


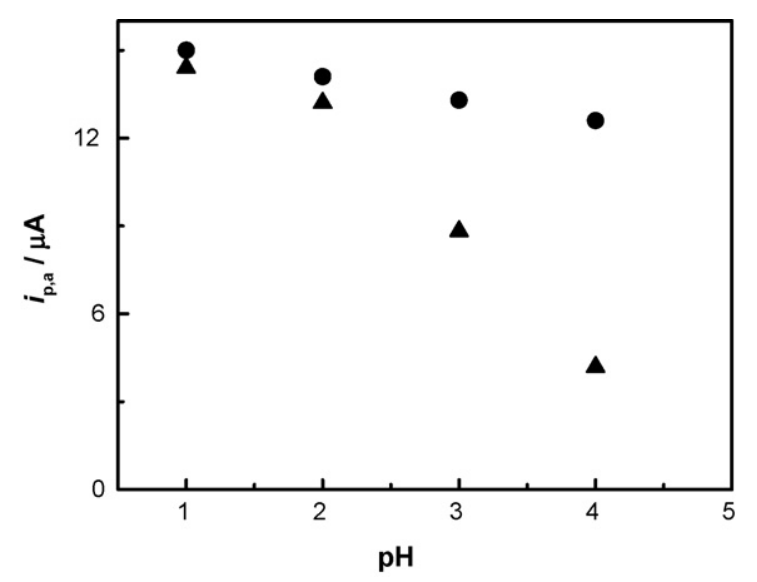

Fig. 2. Oxidation peak current, $i_{\mathrm{pa}}$, measured by cyclic voltammetry in sulfuric acid/sodium sulfate $\left(0.1 \mathrm{~mol} \mathrm{~L}^{-1}, \mathrm{pH} \mathrm{1-4}\right)$ in a solution containing $5.0 \times 10^{-4} \mathrm{~mol} \mathrm{~L}^{-1}$ ambroxol: ( $)$ 1st cycle and ( $\mathbf{\bullet}) 11$ th cycle.

pH range from 2 to 12 , demonstrating that the oxidation potential is strongly $\mathrm{pH}$-dependent, see inset of Fig. 1. The corresponding value of the anodic transfer coefficient $\alpha_{\mathrm{a}}$ of $0.72 \pm 0.09$ calculated from the slope of this plot is very close of that value found by Habib and Zayed [21] of $0.76 \pm 0.04$ for an irreversible reduction process involving the transfer of one electron and one proton in Britton-Robinson buffer solution.

From voltammetric studies of ambroxol and the electrochemical oxidation of clenbuterol (which has a structure very similar to ambroxol) [41,42], Demircigil et al. [22] proposed a mechanism for the oxidation process of ambroxol. According to these authors, this process involves the oxidation of the amine group to form a radical cation, two of which react head to head to form a dimer. This dimer is more easily oxidized than ambroxol during the second cycle of the potential sweep. Tamba and Torreggiani [43] investigated the chemical properties of ambroxol under irradiation. They demonstrated that ambroxol is a good scavenger of water radicals, especially of $e_{\text {aq }}$ and $\bullet \mathrm{OH}$ species. In their studies it was verified that - $\mathrm{OH}$ radical attack was preferentially addressed to the ring positions occupied by bromine atoms, generating hydroxycyclohexadienyl radicals.

Our experiments showed higher anodic currents when the $\mathrm{pH}$ is increased and at less positive oxidation potentials. Unfortunately, in alkaline medium the irreproducibility of the measurements was very high and the response for successive cyclic voltammograms decreased very rapidly. In acidic medium, more reproducible results were obtained but a very narrow linear range of response was observed. This behavior made us search for different supporting electrolytes, based on sulfuric, acetic and hydrochloric acids. Amongst them, experiments performed in sulfuric acid medium lead to the most favorable results. To evaluate the best working $\mathrm{pH}$, experiments involving sulfuric acid/sodium sulfate were performed.

Fig. 2 shows the results of cyclic voltammetry experiments carried out using $5.0 \times 10^{-3} \mathrm{~mol} \mathrm{~L}^{-1}$ ambroxol in sulfuric acid/sodium sulfate solution ( $\mathrm{pH} 1-4)$ at a carbon film working electrode. Only a slight decrease of the peak current values was observed after 11 cycles at $\mathrm{pH} 1$. However at $\mathrm{pH} 4$ the decrease of the signal was significant ( $33 \%$ ) compared with the initial current value. The reason for this decrease of signal is not obvious, but probably at this $\mathrm{pH}$, the products generated during the oxidation process remain on the electrode, partially blocking its surface.

Based on the results presented in Fig. 2, as well as on other experiments not shown here, and considering mainly the good reproducibility and the linear response range obtained in $0.1 \mathrm{~mol} \mathrm{~L}^{-1} \mathrm{H}_{2} \mathrm{SO}_{4}$, this condition was selected for all the experiments performed in the following experiments.

Fig. 3 presents cyclic voltammograms corresponding to increasing additions of ambroxol in $0.1 \mathrm{~mol} \mathrm{~L}^{-1}$ sulfuric acid solution at scan rate $100 \mathrm{mV} \mathrm{s}^{-1}$ on carbon film electrode. The signal obtained for each concentration of ambroxol was very stable and reproducible. A very good linear relationship between anodic current and ambroxol concentration $\left(1.0 \times 10^{-4}-2.0 \times 10^{-3} \mathrm{~mol} \mathrm{~L}^{-1}\right)$ was observed, as can be seen in the inset of Fig. 3. These results confirmed the usefulness of sulfuric acid as supporting electrolyte in the analysis of ambroxol.

The variation of anodic current with scan rate, from 0.01 to $0.9 \mathrm{~V} \mathrm{~s}^{-1}$ was investigated in the same medium. As the scan rate was increased, the peak potential shifted towards more positive values, confirming the irreversibility of the process. The oxidation current values varied linearly with the square root of the scan rate $\left(v^{1 / 2}\right)$, with a slope of 0.38 (correlation coefficient of 0.999 ), suggesting a diffusion-controlled process. Moreover the variation of logarithm between the oxidation current and the scan rate presented a slope of 0.47 (correlation coefficient of 0.999 ) because of the diffusive component, close to the theoretical value of 0.5 for a diffusioncontrolled process [44]. The slope values obtained in the present study are in very good agreement with those found by Demircigil et al. [22]: 0.37 (plot of anodic current with square root of the scan rate) and 0.46 (variation of logarithm between the anodic current and the scan rate) in Britton-Robinson buffer solution.

The electrochemical oxidation of ambroxol was also investigated using two other electrode materials in the presence of $2.0 \times 10^{-4} \mathrm{~mol} \mathrm{~L}^{-1}$ ambroxol in $0.1 \mathrm{~mol} \mathrm{~L}^{-1}$ sulfuric acid solution. Results obtained for carbon film, glassy carbon and platinum electrodes are shown in Fig. 4. For platinum electrodes, it was not possible to obtain a well-defined anodic peak. For both carbon film and glassy carbon electrodes an anodic wave was observed during the forward sweep, corresponding to ambroxol oxidation (around $+1.1 \mathrm{~V} v s . \mathrm{Ag} / \mathrm{AgCl}$ ) and a cathodic process in the reverse sweep was also observed. The magnitude of the anodic current density at the carbon film electrode was greater than at glassy carbon. This is a clear indication that a more favorable electrochemical performance for the oxidation of ambroxol is achieved on the carbon film surface.

\subsection{Flow injection parameters}

To establish the best conditions for flow injection analysis of ambroxol, the influence of parameters such as flow rate and injected sample volume on the amperometric signal was evaluated using

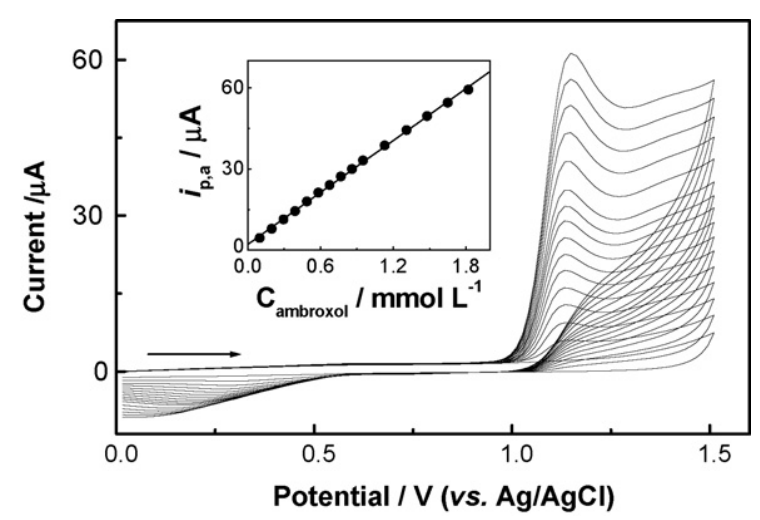

Fig. 3. Cyclic voltammograms measured with the carbon film electrode $\left(A=0.17 \mathrm{~cm}^{2}\right)$ in $0.1 \mathrm{~mol} \mathrm{~L}^{-1}$ sulfuric acid for increasing concentrations of ambroxol (from $1.0 \times 10^{-4}$ to $2.0 \times 10^{-3} \mathrm{~mol} \mathrm{~L}^{-1}$ ). Scan rate: $100 \mathrm{mV} \mathrm{s}^{-1}$. 


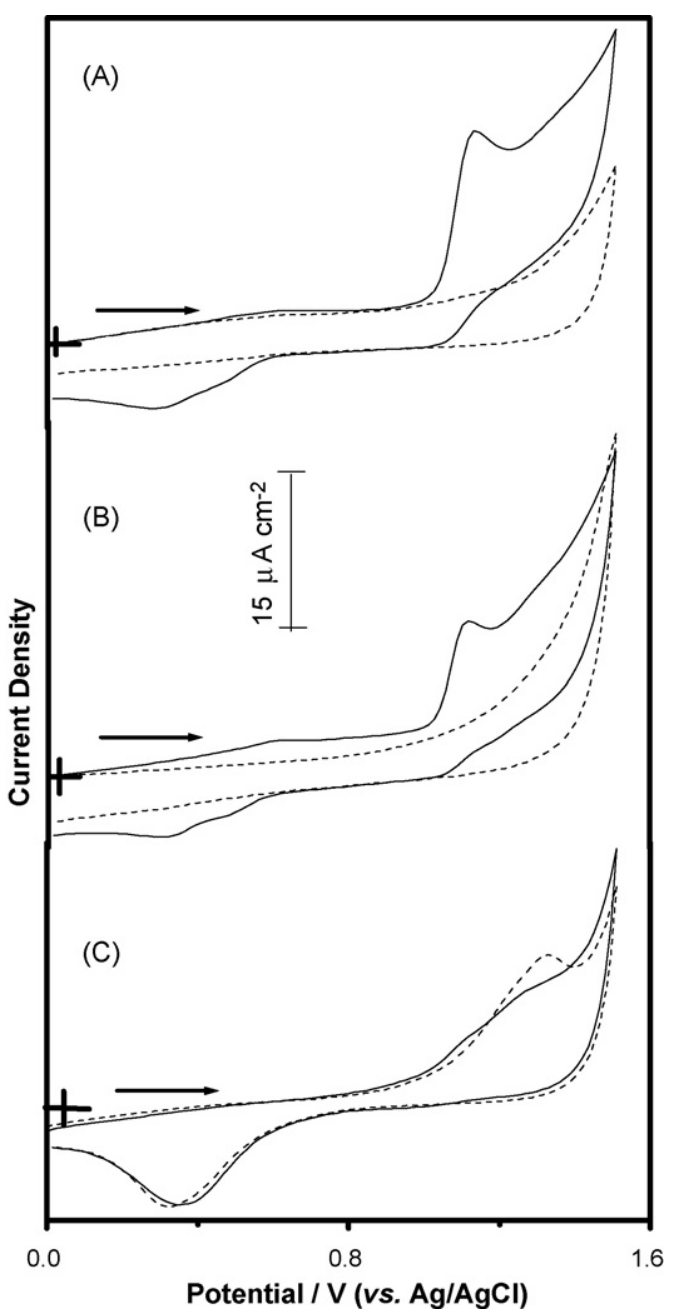

Fig. 4. Cyclic voltammograms at different electrodes: carbon film (A), glassy carbon (B) and platinum (C) in $0.1 \mathrm{~mol} \mathrm{~L}^{-1}$ sulfuric acid solution (dashed line) and in the presence of $2.0 \times 10^{-4} \mathrm{~mol} \mathrm{~L}^{-1}$ ambroxol (solid line). Electrode areas: (A) $0.17 \mathrm{~cm}^{2}$, (B) $0.18 \mathrm{~cm}^{2}$ and (C) $0.07 \mathrm{~cm}^{2}$. Scan rate, $100 \mathrm{mV} \mathrm{s}^{-1}$.

a solution containing $5.0 \times 10^{-6} \mathrm{~mol} \mathrm{~L}^{-1}$ of the analyte diluted in $0.1 \mathrm{~mol} \mathrm{~L}^{-1}$ sulfuric acid. Taking into account the cyclic voltammetric studies (Fig. 3) and hydrodynamic experiments (not showed), an applied potential of $+1.15 \mathrm{~V}(v s$. $\mathrm{Ag} / \mathrm{AgCl})$ was selected for all FIA experiments.

The effect of flow rate (from 1.0 to $5.0 \mathrm{~mL} \mathrm{~min}^{-1}$ ) on the analytical signal was evaluated, utilizing a sample volume of $100 \mu \mathrm{L}$. The current increased with flow rate until $4.0 \mathrm{~mL} \mathrm{~min}^{-1}$ and remained virtually constant for higher values. When the flow rate was

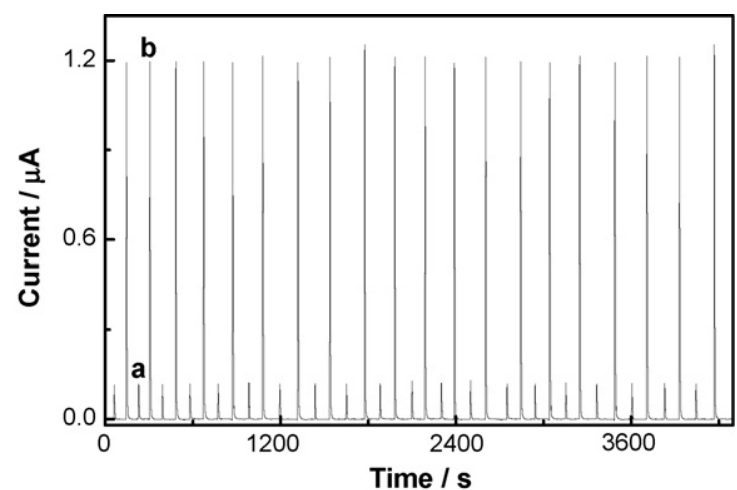

Fig. 5. FIA results for alternate injections of (a) $6.0 \times 10^{-6} \mathrm{~mol} \mathrm{~L}^{-1}$, (b) $6.0 \times 10^{-5} \mathrm{~mol} \mathrm{~L}^{-1}$ ambroxol in $0.1 \mathrm{~mol} \mathrm{~L}^{-1}$ sulfuric acid supporting electrolyte. Applied potential $+1.15 \mathrm{~V} v$ s. $\mathrm{Ag} / \mathrm{AgCl}$, flow rate $2.0 \mathrm{~mL} \mathrm{~min}^{-1}$, sample loop $100 \mu \mathrm{L}$.

increased above $2.0 \mathrm{~mL} \mathrm{~min}^{-1}$ there was a decrease in repeatability, the relative standard deviation (R.S.D.) was $1.0 \%$ for $2.0 \mathrm{~mL} \mathrm{~min}^{-1}$ compared with $2.5 \%$ for $3.0 \mathrm{~mL} \mathrm{~min}^{-1}$. The R.S.D. did not significantly improve at flow rates below $2.0 \mathrm{~mL} \mathrm{~min}^{-1}$. Taking into account these aspects, a flow rate of $2.0 \mathrm{~mL} \mathrm{~min}^{-1}$ was selected as the most favorable due to its good repeatability and satisfactory sampling rate (50 determinations per hour).

The effect of sample volume injected in the stream was also evaluated using volumes from 50 up to $300 \mu \mathrm{L}$. The amperometric signal increased linearly with sampling loops from 50 until $150 \mu \mathrm{L}$. A volume of $100 \mu \mathrm{L}$ was adopted because it represented the minimum sample volume that gave good repeatability and was the most favorable taking into account the sampling frequency.

\subsection{Analytical characteristics}

In order to establish the linear working range, a series of experiments was performed with a standard solution of ambroxol. All ambroxol standard solutions were prepared by dilution from a $1.0 \times 10^{-2} \mathrm{~mol} \mathrm{~L}^{-1}$ stock solution. This study showed a wide linear range from $5.0 \times 10^{-7}$ to $3.5 \times 10^{-4} \mathrm{~mol} \mathrm{~L}^{-1}$, with calibration plot intercept at $0.025 \pm 0.011 \mu \mathrm{A}$ and a slope of $18.76 \pm 0.11 \mu \mathrm{A} / \mathrm{mmol}$, with a correlation coefficient of 0.999 . The estimated detection limit was $7.61 \times 10^{-8} \mathrm{~mol} \mathrm{~L}^{-1}$ (three times the blank standard deviation/slope) and the quantification limit was calculated as $2.53 \times 10^{-7} \mathrm{~mol} \mathrm{~L}^{-1}$

Fig. 5 presents the FIA-amperometric responses for 40 successive and alternated injections of ambroxol solutions containing $6.0 \times 10^{-6}$ and $6.0 \times 10^{-5} \mathrm{~mol} \mathrm{~L}^{-1}$ of ambroxol. A very good repeatability of the current peaks for both concentrations is seen in this experiment. In this series of injections, relative standard deviations (R.S.D.) of 3.0 and $1.5 \%$ for $6.0 \times 10^{-6}$ and $6.0 \times 10^{-5} \mathrm{~mol} \mathrm{~L}^{-1}$

Table 1

Results obtained after analyses of ambroxol in four commercial pharmaceutical samples by FIA, UV spectrophotometry (307 nm) [21,22] and potentiometric titration [23]

\begin{tabular}{|c|c|c|c|c|c|}
\hline Sample & Composition & $\begin{array}{l}\text { Labeled value } \\
(\mathrm{mg} / 5 \mathrm{~mL})\end{array}$ & $\begin{array}{l}\text { Amperometry } \pm \text { S.D. }{ }^{a} \\
(\mathrm{mg} / 5 \mathrm{~mL})\end{array}$ & $\begin{array}{l}\text { Spectrophotometry } \pm \text { S.D. }{ }^{a} \\
(\mathrm{mg} / 5 \mathrm{~mL})\end{array}$ & $\begin{array}{l}\text { Titration } \pm \text { S.D. } \\
(\mathrm{mg} / 5 \mathrm{~mL})\end{array}$ \\
\hline 1 & $\begin{array}{l}\text { Ambroxol hydrochloride, sorbitol, glycerol, essence, } \\
\text { benzoic acid, menthol, sacarine, propylene glycol }\end{array}$ & 30 & $30.6 \pm 0.2$ & $30.4 \pm 0.4$ & $31.4 \pm 0.8$ \\
\hline 2 & $\begin{array}{l}\text { Ambroxol hydrochloride, sorbitol, citric acid, } \\
\text { glycerol, methylparaben, essence, propylparaben }\end{array}$ & 30 & $30.1 \pm 0.3$ & $29.8 \pm 0.3$ & $29.7 \pm 0.4$ \\
\hline 3 & $\begin{array}{l}\text { Ambroxol hydrochloride, sorbitol, glycerol, benzoic } \\
\text { acid, menthol, propylene glycol, aroma, tartaric acid }\end{array}$ & 15 & $15.3 \pm 0.2$ & $14.8 \pm 0.3$ & $15.5 \pm 0.4$ \\
\hline 4 & $\begin{array}{l}\text { Ambroxol hydrochloride, citric acid, aroma, } \\
\text { methylparaben, propylparaben, sorbitol, glycerol }\end{array}$ & 15 & $15.5 \pm 0.3$ & $15.1 \pm 0.2$ & $15.2 \pm 0.2$ \\
\hline
\end{tabular}

a Average \pm standard deviation for three determinations. 


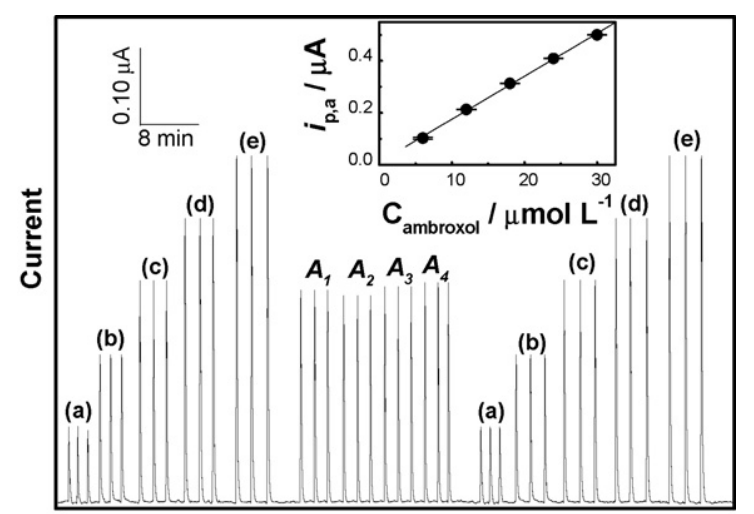

Time

Fig. 6. Analyses of ambroxol samples $A_{1}-A_{4}$ using carbon film electrode in $0.1 \mathrm{~mol} \mathrm{~L}^{-1}$ sulfuric acid supporting electrolyte. Inset: calibration curve obtained from injections of (a) 6.0 , (b) 12 , (c) 18 , (d) 24 , (e) $30 \mu \mathrm{mol} \mathrm{L}^{-1}$ ambroxol standard solutions. Applied potential $+1.15 \mathrm{~V} v$ s. $\mathrm{Ag} / \mathrm{AgCl}$, flow rate $2.0 \mathrm{~mL} \mathrm{~min}^{-1}$, sample volume $100 \mu \mathrm{L}$.

ambroxol solutions, respectively, were obtained. These results demonstrate that there is no memory effect between successive injections, as well as the good performance of the working electrode under these conditions, since no decrease of the signal of the carbon film electrode was observed after 40 injections.

To estimate the effect of potentially interfering species present in the syrup constitution, the full composition of the studied syrups was accessed; the composition of each syrup is listed in Table 1. Citric acid and benzoic acid excipients in the pharmaceuticals investigated are the most likely to cause interferences. To evaluate their effects, a solution containing $1.0 \times 10^{-5} \mathrm{~mol} \mathrm{~L}^{-1}$ ambroxol (in $0.1 \mathrm{~mol} \mathrm{~L}^{-1}$ sulfuric acid supporting electrolyte) was utilized. For benzoic acid, addition of $1.0 \times 10^{-5} \mathrm{~mol} \mathrm{~L}^{-1}$ to the ambroxol solution (ratio 1:1) does not cause any change and a second addition corresponding to $1.0 \times 10^{-4} \mathrm{~mol} \mathrm{~L}^{-1}$ (10-fold more benzoic acid than ambroxol) causes an increase of only $2 \%$. The same strategy was used for citric acid: the first addition does not show almost any effect, but when $1.0 \times 10^{-4} \mathrm{~mol} \mathrm{~L}^{-1}$ was added, an increase of $\sim 7 \%$ in the current was verified. However, such a high concentration of citric acid cannot be found in any pharmaceutical formulation of ambroxol. The titration curves shown clearly that for all the samples, the volume of $\mathrm{HCl}$ consumed to neutralize citric acid $\left(\mathrm{p} K_{\mathrm{a}_{1}}=3.14 ; \mathrm{p} K_{\mathrm{a}_{2}}=4.77\right)+$ benzoic acid $\left(\mathrm{p} K_{\mathrm{a}}=4.19\right)$ was smaller than the volume consumed until attain the equivalence point corresponding to ambroxol $\left(\mathrm{pK}_{\mathrm{a}_{1}}=6.84\right)$ neutralization. Additional tests were done with almost all the other constituents listed in Table 1 and do not lead to any change in response.

\subsection{Analyses of ambroxol samples}

To demonstrate the applicability of the proposed method, four different commercial syrup formulations containing ambroxol were analyzed. The results obtained using FIA-amperometry were compared with those from the spectrophotometric procedure $[21,22]$ and with the potentiometric acid/base titration. Potentiometric titration is the methodology recommended in the British Pharmacopoeia for ambroxol quantification [24].

Fig. 6 shows a series of typical results (amperometric signals) obtained for syrup samples, preceded and followed by a series of injections of ambroxol standard solutions (from $6.0 \times 10^{-6}$ to $3.0 \times 10^{-5} \mathrm{~mol} \mathrm{~L}^{-1}$ ). The concentration of ambroxol in the syrup samples was evaluated using the calibration plot shown in the inset of Fig. 6.
The results of the analyses of all syrup samples obtained for amperometry, spectrophotometry and potentiometric titration methods are summarized in Table 1, together with the corresponding standard deviations, calculated from three independent measurements for each sample. The composition of each pharmaceutical product is also included in order to show the components present, as well as the amount of ambroxol expected for each sample. Relative differences of the mean values between -0.4 and $+2.7 \%$ were calculated by comparison of the results found employing the three methodologies, but agreement between the proposed method and the other two methods is very good.

\section{Conclusion}

The results obtained in this work demonstrate the potentiality of flow injection analysis combined with amperometric detection for the rapid quantification of ambroxol in pharmaceutical formulations. The proposed method allows simple and precise analyses without any sample pretreatment, such as filtration, extraction or derivatization. The carbon film sensor shows a better performance for determination of this analyte, compared to other electrodes, such as glassy carbon and platinum electrodes. Moreover, the carbon film sensor provides a low detection limit, good selectivity and good reproducibility. Other additional advantages that make this new sensor attractive for quality control applications are its low cost, ease of preparation and the fact that it can be used as a disposable sensor.

\section{Acknowledgements}

The authors gratefully thank the financial support from Brazilian Foundation (CNPq-proc. 141530/2004-9 and 304031-85-2) and Fundação para a Ciência e Tecnologia (FCT) Portugal, ICEMS (Research Unit 103). The donation of pure ambroxol by Arvensis from Brazil is acknowledged. This work was partially supported by the Renami, Sanmuti and $\mathrm{IM}^{2} \mathrm{C}$ projects.

\section{References}

[1] W.H. Martindale, in: J.E.F. Reynold (Ed.), The Extra Pharmacopoeia, 29th ed., The Pharmaceutical Press, London, 1989, p. 904.

[2] E. Sumarlik, G. Indrayanto, J. Liq. Chromatogr. Related Technol. 27 (2004) 2047.

[3] M.L. Qi, P. Wang, R.H. Cong, J.J. Yang, J. Pharmaceut. Biomed. 35 (2004) 1287.

[4] G. Bazylak, L.J. Nagels, J. Pharmaceut. Biomed. 32 (2003) 887.

[5] H. Kim, J.Y. Yoo, H.J. Lee, K.R. Lee, J. Pharmaceut. Biomed. 32 (2003) 209.

[6] A. Zarzuelo, M.L. Sayalero, F.G. López, J.M. Lanao, J. Liq. Chromatogr. Related Technol. 24 (2001) 1007.

[7] M. Heinanen, C. Barbas, J. Pharmaceut. Biomed. 24 (2001) 1005.

[8] J.E. Koundourellis, E.T. Malliou, T.A. Broussali, J. Pharmaceut. Biomed. 23 (2000) 469.

[9] B.D. Kiss, K.B. Nemes, I. Urmos, J. Szunyog, I. Klebovich, Chromatographia 51 (2000) S217.

[10] M. Nobilis, J. Pastera, D. Svoboda, J. Kvetina, K. Macek, J. Chromatogr.-Biomed. 581 (1992) 251.

[11] V. Brizzi, U. Pasetti, J. Pharmaceut. Biomed. 8 (1990) 107.

[12] M.H.A. Botterblom, T.J. Janssen, P.J.M. Guelen, T.B. Vree, J. Chromatogr.-Biomed. 421 (1987) 211.

[13] M. Pospisilova, M. Polasek, V. Jokl, J. Pharmaceut. Biomed. 24 (2001) 421.

[14] T. Perez-Ruiz, C. Martinez-Lozano, A. Sanz, E. Bravo, J. Chromatogr. B 742 (2000) 205.

[15] T. Perez-Ruiz, C. Martinez-Lozano, A. Sanz, E. Bravo, J. Chromatogr. B 692 (1997) 199.

[16] M.S. Hwang, S. Cho, H. Chung, Y.A. Woo, J. Pharmaceut. Biomed. 38 (2005) 210.

[17] R. Szostak, S. Mazurek, J. Mol. Struct. 704 (2004) 229.

[18] Z. Dincer, H. Basan, N.G. Goger, J. Pharmaceut. Biomed. 31 (2003) 867.

[19] G. Indrayanto, R. Handajani, Drug Dev. Ind. Pharm. 20 (1994) 1639.

[20] L. Colombo, F. Marcucci, M.G. Marini, P. Pierfederici, E. Mussini, J. Chromatogr.Biomed. 530 (1990) 141.

[21] I.H.I. Habib, S.I.M. Zayed, Pharmazie 60 (2005) 193.

[22] B.T. Demircigil, B. Uslu, Y. Ozkan, S.A. Ozkan, Z. Senturk, Electroanalysis 15 (2003) 230. 
[23] F.J. Flores-Murrieta, C. Hoyo-Vadillo, E. Hong, G. Castañeda-Hernandez, J. Chromatogr.-Biomed. 490 (1989) 464.

[24] British Pharmacopoeia, vol. I, The Stationery Office, London, 2005, pp. 106- 107.

[25] D. Satinsky, J. Huclova, R.L.C. Ferreira, M.C.B.S.M. Montenegro, P. Solich, J. Pharmaceut. Biomed. 40 (2006) 287.

[26] D. Satinsky, L.M.L. Dos Santos, H. Sklenarova, P. Solich, M.C.B.S.M. Montenegro, A.N. Araujo, Talanta 68 (2005) 214

[27] J.L.M. Santos, A. Clausse, J.L.F.C. Lima, M.L.M.F.S. Saraiva, A.S. Rangel, Anal. Sci. 21 (2005) 461

[28] N.T. Abdel-Ghani, S.H. Hussein, Farmaco 58 (2003) 581.

[29] C.M.A. Brett, L. Angnes, H.D. Liess, Electroanalysis 13 (2001) 765.

30] O.M.S. Filipe, C.M.A. Brett, Electroanalysis 16 (2004) 994.

[31] O.M.S. Filipe, C.M.A. Brett, Talanta 61 (2003) 643.

[32] C. Gouveia-Caridade, R. Pauliukaite, C.M.A. Brett, Electroanalysis 18 (2006) 854

[33] M. Florescu, C.M.A. Brett, Talanta 65 (2005) 306.
[34] M.E. Ghica, C.M.A. Brett, Anal. Chim. Acta 532 (2005) 145.

[35] R. Pauliukaite, M.E. Ghica, C.M.A. Brett, Anal. Bioanal. Chem. 381 (2005) 972.

[36] M.E. Ghica, C.M.A. Brett, Electroanalysis 18 (2006) 748.

[37] R. Pauliukaite, M. Florescu, C.M.A. Brett, J. Solid State Electrochem. 9 (2005) 354.

[38] M. Florescu, C.M.A. Brett, Anal. Lett. 37 (2004) 871.

[39] M.E. Ghica, C.M.A. Brett, Anal. Lett. 38 (2005) 907.

[40] F.S. Felix, C.M.A. Brett, L. Angnes, J. Pharmaceut. Biomed. 43 (2007) 1622.

[41] S. Moane, J.R.B. Rodriguez, A.J.M. Ordieres, P.T. Blanco, M.R. Smyth, J. Pharmaceut. Biomed. 14 (1995) 57.

[42] G.J. McGrath, E. O'Kane, W.F. Smyth, F. Tagliaro, Anal. Chim. Acta 322 (1996) 159.

[43] M. Tamba, A. Torreggiani, Radiat. Phys. Chem. 60 (2001) 43.

[44] D.K. Gosser Jr., Cyclic Voltammetry: Simulation and Analysis of Reaction Mechanisms, VCH Publishers Inc., New York, 1993. 